\title{
Specifics of Work with Blind Musicians-Performers in a Special Piano Class
}

\author{
Experience, Problems, Solutions
}

\author{
Antonova Julia \\ Music Department \\ Russian State Specialized Arts Academy \\ Moscow, Russia \\ e-mail: gsiivostr@mail.ru
}

\author{
Kalitzky Vitaly \\ Music Department \\ Russian State Specialized Arts Academy \\ Moscow, Russia
}

\begin{abstract}
The article considers the issues of professional preparation of blind performers in a specialized piano class. The authors specify three main stages, which acutely show the specifics of work with the blind performers: the stage of acquaintance with the music work, the stage of work with the music work, the stage of stage rehearsals and performance at the concert stage. The question of repertoire choice and the specifics of learning the notes by Louis Brail system, the role of combined listening with the teacher, and imaginary associations in order to form a complete image with a blind performer is particularly stressed. The necessity of focusing on the facture-tembre parts of the music fabric of the piece, the importance of much time for rehearsals is stressed. The authors show that it is quite realistic to prepare such kind of musicians for professional activity.
\end{abstract}

\section{Keywords—piano; blind performer; professional teaching}

\section{INTRODUCTION}

Professional activity of a musician-performer exists in a great variety of kinds and forms. Still, essentially and psychologically, it may be subdivided into two paradigms: music work studying and public concert performance.

For the time criteria these parts are not equal — a short moment of a creative act is preceded by the long, thoughtful and multi-aspect work of a musician. It will not be an exaggeration to say that a particular process of work that represents the main essential part of creative life of a practicing musician forms his performing image, represents a greater part of a creative life of a musician, and defines perspectives of his professional achievements.

Within the frames of this article the authors will attempt, based on their teaching experience at the specialized artistic academy, to analyze some aspects of work with blind musicians.

Any differentiation of a complex process of studying musical work into the following stages is very artificial and may be discussed by a number of examples, connected with individual characteristics of a particular performer. Still many practicing musicians and researchers specify four stages of this work: music material learning stage, the forming of the first «perfect» idea of the music composition; the stage of implementation of the idea into practice with the special performing means; and the concert performing preparation stage.

Consideration and analysis of this very specific problem of professional preparation of the performers with limited sight ability brings us to the following question: how much do these specifics transform the methodology of work with the music work?

\section{The Stage of MAterial LEARNING OF THE MusiC WORK}

The choice of material as a particular start point of performing activity is extremely important for the forming of the musician's professional qualities. Are there technically or emotionally unacceptable music works for the blind musicians` performance?

In piano music literature there're particular methods, which are extremely difficult for a blind pianist. First of all, it is a quick hand movement for large distances, especially in the accords. It is necessary to say that some forms of arpeggio have double notes. To their own mind, «uneasy» technical moments should not prevent the performer from working with it. The teacher's and the student's efforts should be directed towards ways of overcoming the difficulties in feeling the keyboard. At the same time the detailed choice of repertoire for a blind performer may ruin his confidence and self-respect.

It is not a secret that the blind pianists sometimes play the piano very cautiously. This situation is based on a number of reasons; first of all, a learned attitude of distrust to the outside world. The result of this psychological factor is a particular performer's tightness, which prevents showing his temperament, his thoughts and his feelings. But it does not mean that music works that demand obvious emotional and personal involvement should be excluded from the repertoire. The other thing is that the teacher should be particularly attentive to this problem and help the student very tactfully. 
Yet, the only choice of the repertoire that should be excluded are the Avant-guard and post-Avant-guard tendencies of the composer's activity. They contain untraditional forms of piano playing (stringplaying, active performing outside the instrument, using the visual aids, etc).

The initial stage of learning the music work forms the future complete music image. The notes get their life and the musician's imagination forms the image of the composer. Many pianists mark the importance of the first acquaintance with the music work, which allows them to understand the whole material in general and to get the composer's main ideas. M. Grinberg says: «I start playing immediately. Before I learn what I play, I'm trying to get the whole idea and the features of the image. So, I don't start learning, but I just play - with false notes, dirty, just to get the understanding of what it will be» [1, 178]. G. Ginsbourg had a similar position: "The first stage is just an acquaintance with the material at the instrument. If I've never heard this piece, I study it, learn the thematic material, how it is worked. At the first stage I don't try to show the maximum accuracy, but I try to imagine what I should get» $[1,178]$.

Crucially, blind performers don't have this sketch experience of the studied material, since they use the reliefpoint Louis Brail notes system. Brail`s notes studying is an extremely hard and difficult process, which suggests studying only fragments of the material. This stage of the formation of the music image may contain listening of the recordings, which partly compensates a blind student the inaccessible visual experience.

Nevertheless, this solution is not perfect, as there's a danger of imposing some convincing interpretation instead of the creation of your own vision of the composition. Creative cooperation between the author and the student is necessary in order to create an idea of the content of the music work, based on the individual and personal characteristics of the student. Combined listening of the maximum number of recordings (one or two recordings will give a loop-sided idea of the composition), pedagogical demonstration, and literature associations are a good guarantee of the successful work.

\section{COMPOSER`S IDEA REALIZATION STAGE}

Blind student's practical work on decoding the notes material is based on Brail's system (a popular way of decoding the notes «from the hands», meaning the repetition of the played material by the student is not considered here because of its complete pedagogical incompliance.) Certainly, Brail`s system in many ways is not perfect, but we see no reasons to concentrate on its drawbacks, since there`s no other way of learning the notes for blind students. One should realistically appraise this way of material learning, as it impacts the following stages of artistic performing. The thing is that relief-point script allows music text to be read only step-by-step, marking short enough time horizontal extracts. Besides, multi-voice piano facture suggests division of Brail's music body into vertical elements, so that its every element can be described separately. Thus, these fragment-mosaic structures can be united into complete image only in the imagination of a blind student. We should mark that such work demands a high concentration and does not allow a performer to concentrate on expressive sides of the music text, which is one of the main obstacles in material learning as a semiotic structure. In our opinion, the peculiarity of the initial stage of teaching of blind musicians has certain results. One can suggest that one of the reasons of certain intellectualism and balance, which blind musicians ' performance is marked, is a special way of decoding of music material. At a certain stage the text is imagined as separated technical elements. We should mention, however, that we speak not only about common tendencies, but also of every particular case and individual characteristics of the students.

Based on the dialectic approach to any phenomenon, each of the elements is not equal to itself and is contradictory; its drawbacks are at the same time its strong points, we should mark that obvious disadvantages of reading a note text by Brail text also has its positive and negative sides.

As it had already been marked, a blind pianist at the stage of decoding of music text faces the fragmented disintegration of multi-level composition. M.S. Filatova's remark on this topic is essential: «Music composition... turns to the performer first with its facture side, where from the first moment of its sounding every voice, every accord or layer become precious» $[5,239]$. Indeed, for a seeing pianist music composition appears complete, the comparative parts are thoroughly studied; while a blind performer recreates the completeness by means of the complex addition of separate elements of the text. Thus we conclude that a seeing pianist has a kind of deductivemusical thinking and the seeing one - inductive-musical thinking, which defines some stages of work.

Inevitable for a pianist fragmentary studying the music text and the special way of writing (by voices) at the very first stage gives an opportunity for deeper realization of the structural logics and the expressiveness of the piano performance. Besides, it becomes a work stimulus on finding the relief and background material of the piano as a space instrument. According to S.E. Feinberg: «A pianist reproduces not only a melody or a voice, but a complete harmonic and polyphonic material of the composition. It depends on a musician to make this material obvious or dimmed, bright or silent. Expressing polyphonic voices, the pianist instruments the music, representing to all elements a different role of colorful sounding and general colorite» [6, 104]. This way of learning the text guarantees a special attentive attention to each multi-layer piano expression and fixes in memory its individual characteristics. Direction of such «orchestra» work is finding relief and background components in the sound material of the music, its tembre personification, colorist differentiation of sounding is able to 
widen and enrich the pianist's idea of the scale of the instrument's constructive-expressive opportunities. In this meaning a thorough work of the music text on Brail system works as the basis for deep realization of the composition.

Some other specifics of decoding of the music composition with the help of Brail system should also be discussed. The thing is that a blind performer studying the notes should memorize it by heart at once. Return to some fragment for specification is a very long and difficult process. Logically, in this case special attention is needed for every text detail. According to our observations, such thorough and thoughtful work works as a solid basis for reliable memorization, so blind performers actually have no problems with forgetting the material at a concert.

Another specific problem is a formation of movement skills with the blind performers. If you remember, we discussed how to visually distinguish a blind person: his movements are a bit brisk or lacking of plastics as a result of lack of confidence. Such movements in everyday life are automatic and we can suggest that, being projected on music performing, they can negatively effect the achievement of professional results.

While «the movement of the performer on the piano may have its own expressiveness», according to S.E. Fineberg, «then we should consider it as a way, which is necessary to get the sound from the instrument and a emotion-expressing gesture» $[6,183]$.

Professional performer's skills are worked by the pianist on the basis of visual observations at the manner of playing on the piano of this or that performer, by its own experience and finally, by a correspondence of this or that movement to this or that particular music image. A blind performer lacks such an opportunity and, according to our observations, seldom realizes emotional-artistic content of the sounding with the particular methods of playing. At the same time, the definition of the very kind of movement (for example, gracious, flying, slow), does not have any meaning for them. The necessity of realization of tight connection between the quality and sound characteristics with the complex of movements may seem to be obvious, but for the blind performer, coordination of the hearing and movement sensations is particularly difficult.

For a blind person sound becomes the main source of information. In spite of the fact that physiology does not find any signs of special music development of the blind, we should acknowledge that the result of the constant preparation of the ear is that blind people react more acutely to the slightest sound details. Practical experience allows us to state the special ability of the students to distinguish the slightest sound details. This is particularly precious for a musician, quality may stimulate his creative searchings in the area of sound expressiveness.

A blind musician, partly by intuition and by recommendations of the teacher, organizes the work of his movement performer's apparatus on the following principle: from the effect of reproduced sound to the necessary movement, which visual characteristics are impossible.

The plastics of movements, which is typical for a particular emotional state, demands specification for a blind person, who is no capable of the idea.

In order to create an idea of expressiveness of plastic movements we use the work method, which can be characterized as «a plastic study on the motives of the composition». This conductor's approach, containing the task to express emotional meaning of the music by hands, allows the ideas and sensations of general tendencies of the music to be fixed. Speaking about particular methods of sound extractions the specifics of its performance by the blind pianists, we should express the following. Taking into account the opinion of some outstanding performers and teachers about the legato sound: «The lightness of the sound is achieved by a special way of touching the keys in a particular way. The essence of it is to touch the keys, to glue to it not only by fingers, but by the whole hand» $[3,21]$. «At the cantilena performance the fingers should be kept as close as possible to the keys and to try the maximum contact with the keyboard» $[4,53]$. A number of ideas, which are kept in these quotations, are very much similar to those that characterize the process of an acquaintance of a blind person with a particular object. Definition of a quality and characteristics of the object by touch suggests a close contact with it, and the work of receptors for finding of the micro-texture details. The work with a blind student at the cantilena legato is associated with his memory, fixing the slightest nuances of the sound quality, appearing at the moment of touching the keys. Usually blind performers catch these methods very quickly and are very sensitive to sound characteristics, connected with the depth of the key touch. We used to face such a student's question: how high should a hand be taken from the keyboard for different nuances? With all the seeming professional infancy, the very fact of presence of such questions of a blind musician has very deep grounds. The reason is that taking the hand off the keyboard, even for a moment, for such a performer creates a feeling of uncertainty, which results in muscular tenseness. A tense hand and cautiousness in the taking of a hand from the keyboard leads to briskness of the movements and to a hardness of the sound. A touch scale of a pianist is very wide. "There're thousands ways of extracting a sound from the piano and similar tembre and typical shades of sound» $[6,175]$.

In his research of articulation problems studying the nature of zone strokes, M.M. Imkhanitsky writes about endless artistic-stroke gradations inside their universal classifications [2]. Their realization in the practical work of a performer and the teacher needs to get additional notions - imaginary characteristics, metaphors, association analogies. The sense of these notions is not always clear to the blind performer. 
On the other hand, attempts to reach a necessary result with the help of calculation and amplitude fixation and the movement of the hand are almost impossible. Thus, we have to admit that the main direction in the forming of professional movement skills of a blind pianist is a fine hearing analysis of the coordination moment of the hand movements and sound results. Speaking about priority performing tasks, G. Kogan writes: «the more concentrated is the attention on the purpose of movement and will power, the quicker and more accurate is the automatisation process, the easier finds the body its right way to getting the purposes of our conscience» $[3,24]$.

For deepening and detailization of such work it is necessary to widen the scope of your sound images and analogies. In this sense, a method of comparison of grand piano sounding with different other orchestra instruments is very perspective. Its potential opportunities as one of the ways of performing perfection are highly appreciated by the best representatives of piano art. Attentive studying of different sound analogies will definitely lead a blind pianist to the necessity of incorporation of sounds into reality.

Definitely, such hearing method is not the only one, but to our mind blind musician performance practice specifics from the position of available and potentially efficient methods of work makes it the most productive. The questions that appear during the choosing of performance methods for overcoming technical difficulties are very specific for blind pianists. Detailization of every case is impossible within this article. We'll cover just a few ones.

The famous «stiffness» and permanent rigidity of the playing hand is a general tendency of the performing practice of the blind. It is specified by nearly every researcher of the problem and becomes the main «petra scandali» on the way of virtuoso freedom achievement. Negative qualities appear during the performance of both «slight» and "great» kinds of techniques, but they are formed, in our observations, in the conditions of not enough thought work at the accord material, especially if the performance is connected with long distance hand movement. Here it is necessary to find the necessary solutions for every movement.

A «principle of a position taken in advance» [6, 275], formulated by S. Feinberg, may help the blind pianist's orientation on the keyboard. In our conversations with a potential student we often have to face this idea of presensation/anticipation of every following element.

Priority of the task and its performance solution mobilizes the hand, providing hand preparation to take a new position, and a more detailed and clear performance.

It is recommended to include into the ratio of the performer with the serious eyesight problems exercises, where technical material becomes more and more difficult and uneasy for the performer. It may be performing different kinds of jumps, which will prevent the student from the constant fear of a mistake, which could impact the whole performance picture. Special attention should be given to comfortable application. Our experience of work with blind pianists shows that special uneasiness appears in the moment of putting the fingers in passages, which happens because of lack of visual control of the hand position on the keyboard.

\section{CONCERT PERFORMANCE PREPARATION STAGE}

Psychological preparation for the performance starts with the moment of learning of the composition and ends with pre-concert rules of the performer's behavior. Let's try to cover some specifics of preparation of the blind pianists for the concert. Preparation of a blind pianist may involve the following key moments: general psychological preparation, scenic performance adaptation, work with particular compositions, and situational reaction methods.

Psychological preparation of a blind pianist for the performance first of all includes concentration on the positive moments of his own performance. There're different motivation kinds influencing the pre-concert condition of the performer. It is connected with the personal attitude of a performer to the music compositions, his attitude to the audience and his professional perfection. For a blind performer his self-realization sometimes is the best motivation. That is why psychological support is necessary, it forms in the mind of a blind musician's confidence, stresses his independence and individuality and helps to overcome inferiority complex. Adaptation aspects suggest performance modeling in particular stage conditions: from every scenic movement to concentration of the interior hearing image and the details of the acoustics. For a blind person organizational and technical details are particularly important: where the audience is, how far is the grand-piano from the stage entrance, etc. The slightest «emergency» may take the pianist out of concentration.

That is why it is necessary to have enough rehearsal in the company of the stage assistant. The necessity of concert performance on the suggested instruments is a typical stress factor for any pianist. A blind musician feels all the specifics of the instruments more acutely. Different sized instruments and the slightest construction specifics of the keyboard, like the height and width of the keys, may lead to confusion and discomfort.

The issue of working out the methods of situational reaction covers a lot of aspects, but they are involved into the general professional preparation. Impossibility of reading the notes gives an impulse to the development of improvisational skill. All these skills are necessary to be formed and developed, as they give the sense of freedom and allow a better reaction to different cases during the performance.

\section{CONCLUSION}

In conclusion we should say that attention concentration on specific peculiarities of performance practice of the blind 
musicians reflects the content of the working stage in the meaning of achievable search of the purpose achievement. The purpose itself is the best presentation on stage and it should not have a special attitude to such a performer.

\section{REFERENCES}

[1] L.L. Bochkarjov, "Phylosophy of the Musical Activity". M., Klassika-XXI, 2007;- PP.178, 352.

[2] M.I. Imhanickij, "Novel about Articulation and Pickings in Musical Intoning”. M., Gnesin RAM, 2014;- P.231.

[3] G.M. Kogan, "Issues of Pianism". Sovetsky Kompozitor. M, 1968;PP. 21, 24, 460 .

[4] J.I. Milstein, "K.N. Igumnov about Shopin”. Sovetskaja Muzyka, 1956, No.10, P.53.

[5] M.S. Skrebkova-Filatova, "Texture in Music". M., Muzyka, 1985;PP. 239, 285.

[6] S.E. Feinberg. "Pianizm as Art". M., Muzyka, 1969;- PP. 104, 175, 183, 275, 598 . 